\title{
IMPLEMENTASI LOGIKA FUZZY MAMDANI UNTUK MENENTUKAN KOMPOSISI OPTIMAL PUPUK ORGANIK DAN ANORGANIK NPK PADA TANAMAN MENTIMUN
}

\author{
Fajar Ridwan Analistyawan ${ }^{1}$, Sutrisno ${ }^{2}$, Solichin Zaki ${ }^{3}$ \\ ${ }^{1,2,3}$ Departemen Matematika, Fakultas Sains dan Matematika, Universitas Diponegoro \\ Jalan Prof. Soedarto, SH. Tembalang, Semarang, Indonesia, 50275 \\ Email : ${ }^{1}$ fajar.analistyawan@gmail.com
}

\begin{abstract}
In this article, we have determined the optimal composition of organic fertilizer and NPK inorganic fertilizer for cucumber plants. We have formulated two fuzzy systems which are fuzzy system 1 and fuzzy system 2 . The inputs for fuzzy system 1 are plants' height and the number of leaves where the output is the growth rate. Fuzzy system 2 had input of growth rate and NPK concentration and output of organic fertilizer concentration. By processing the data using fuzzy system, we have compared the cucumber plant with organic fertilizer and NPK to cucumber plant that was used only NPK fertilizer. The result had shown that the cucumber plant with organic fertilizer and NPK was produced the better outcome than the cucumber plants with NPK only.
\end{abstract}

Keywords: Fuzzy Set, Mamdani Fuzzy Logic, Cucumber, NPK Fertilizer, Organic Fertilizer.

\begin{abstract}
Abstrak. Pada artikel ini, telah didapatkan komposisi optimal dari pupuk organik dan pupuk anorganik NPK untuk tumbuhan mentimum. Telah diformulasikan dua sistem fuzzy yang disebut sistem fuzzy 1 dan sistem fuzzy 2. Input untuk sistem fuzzy 1 adalah tinggi tanaman dan banyaknya daun sedangkan outputnya adalah tingkat pertumbuhan. Pada sistem fuzzy 2, inputnya meliputi tingkat pertumbuhan dan konsentrasi NPK sedangkan outputnya adalah konsentrasi pupuk organik. Dengan memproses data pengamatan menggunan sistem fuzzy tersebut, telah diperoleh hasil perbandingan tanaman mentimum dengan pupuk organik dan NPK yang dibandingkan dengan tanaman mentimun yang hanya dipupuk dengan NPK. Hasilnya menunjukkan bahwa tanaman mentimun dengan pupuk organik dan NPK memberikan luaran yang lebih baik daripada tanaman mentimun yang hanya dipupuk dengan NPK.
\end{abstract}

Kata kunci: Himpunan Fuzzy, Logika Fuzzy Mamdani, Mentimun, Pupuk NPK, Pupuk Organik.

\section{PENDAHULUAN}

Logika fuzzy merupakan perluasan dari logika biner, yang memungkinkan nilai keanggotaan dari anggota himpunan fuzzy berada diantara 0 dan 1 [1]. Logika fuzzy sering digunakan dalam sistem pendukung keputusan pada suatu sistem fuzzy. Nilai derajat keanggotaan menjadi ciri utama dari penalaran menggunakan logika fuzzy. Terdapat beberapa model fuzzy yang umum digunakan untuk memodelkan suatu sistem fuzzy, dimana pada artikel 
ini digunakan model fuzzy Mamdani. Pada Model fuzzy Mamdani dalam membentuk sistem fuzzy diperlukan beberapa tahap, yaitu fuzzifikasi, implikasi, inferensi, dan defuzzifikasi [1].

Logika fuzzy dapat digunakan untuk memodelkan situasi di mana orang membuat keputusan dalam masalah yang sangat kompleks sehingga sangat sulit untuk dibuat model matematika [2]. Sistem fuzzy dapat digunakan dalam memecahkan masalah pada kehidupan sehari-hari, misalkan pada lampu lalu lintas, dimana sistem fuzzy digunakan dalam mengontrol lampu lalu lintas agar lebih efektifdengan objek yang dimodelkan adalah jumlah kendaraan pada perempatan jalan [3]. Sistem fuzzy juga dapat digunakan untuk memberikan waktu lebih pada kendaraan darurat seperti ambulan pada persimpangan lalu lintas [4]. Dalam mengatasi lahan parkir, sistem fuzzy dapat digunakan dalam sistem pemarkiran otomatis yang dijadikan algoritma pada sebuah perangkat aplikasi [5]. Sistem fuzzy juga dapat digunakan dalam menentukan lama waktu mecuci pada mesin cuci untuk mengoptimalkan waktu [6].

Mentimun termasuk buah yang bermanfaat dalam kehidupan sehari - hari. Faktor penentu produktivitas tanaman mentimun antara lain faktor iklim, serangan hama, penyakit, dan menurunnya kualitas tanah akibat pemupukan yang kurang tepat [7]. Penggunaan kombinasi POH dan pupuk NPK merupakan salah satu cara untuk meningkatkan produktivitas dari tanaman mentimun. POH memberikan nutrisi pada tanaman lebih lambat dibanding dengan pupuk anorganik, untuk itu perlu dikombinasikan antara $\mathrm{POH}$ dan pupuk anorganik [8]. Dalam masalah budidaya tanaman, sistem fuzzy sering digunakan untuk meningkatkan faktor penentu produktivitas, misalkan kelembaban tanah pada budidaya cabai [9]. Sistem fuzzy juga dapat digunakan dalam menentukan suhu optimal agar jamur memiliki kelembaban yang tepat [10].

Sistem fuzzy Mamdani telah diterapkan diberbagai bidang untuk menyelesaikan masalahmasalah praktis. Pada referensi [11], sistem fuzzy Mamdani telah digunakan untuk menyelesaikan masalah prediksi pada longwall panel roof rock strata sedangkan pada referensi [12], sistem fuzzy Mamdani telah diterapkan untuk pengukuran modulus elastisitas dari intact rocks dan pada artikel [13] telah diselesaikan masalah keamanan ekologi di delta sungai Pearl menggunakan sistem fuzzy Mamdani. Dalam artikel ini mentimun digunakan sebagai objek yang dimodelkan kedalam sistem fuzzy dengan menggunakan metode fuzzy Mamdani dengan defuzzifikasi Centroid. Sistem fuzzy pada artikel ini diformulasikan dan digunakan untuk menentukan kombinasi optimal pupuk organik hayati dan NPK pada tanaman mentimun sehingga mendapatkan produktivitas yang optimal..

\section{METODOLOGI}

Variabel eksperimen yang digunakan sebagai data penelitian adalah tinggi tanaman dan banyak daun. Pengukuran tinggi tanaman mentimun dilakukan pada saat tanaman berusia 27 HST (Hari Setelah Tanam), tanaman diukur dari pangkal batang hingga ujung daun tertinggi menggunakan benang kur kemudian benang diukur menggunakan penggaris. Banyak daun dihitung pada saat tanaman berusia 27 HST (Hari Setelah Tanam), daun yang dihitung adalah daun yang masih bakal daun sampai daun tua yang belum gugur.

Data yang diperoleh diformulasikan kedalam sistem fuzzy yang diselesaikan dengan model fuzzy Mamdani dengan defuzzifikasi metode Centroid. Pada artikel ini diformulasikan 2 sistem fuzzy. Sistem fuzzy 1 digunakan untuk menentukan output tingkat pertumbuhan dari tanaman mentimun dengan input tinggi tanaman dan banyak daun yang telah didapat dari eksperimen, sedangkan sistem fuzzy 2 digunakan untuk menentukan output konsentrasi POH dengan input 
tingkat pertumbuhan yang didapat dari sistem fuzzy 1 dan konsentrasi NPK yang diberikan diawal penanaman.

\section{PENENTUAN KOMBINASI OPTIMAL PUPUK ORGANIK HAYATI DAN PUPUK ANORGANIK NPK}

Perlakuan yang diberikan pada tanaman mentimun adalah perbedaan konsentrasi $\mathrm{POH}$ dan NPK, dimana ada 10 perlakuan yang diulang sebanyak 5 kali, sehingga ada 50 tanaman mentimun sebagai objek eksperimen. Rerata data hasil eksperimen tinggi tanaman mentimun dan banyak daun mentimun tiap perlakuan dapat dilihat pada Tabel 1.

Tabel 1 Rerata Data Hasil Eksperimen

\begin{tabular}{ccc}
\hline Perlakuan Pemupukan & $\begin{array}{c}\text { Rerata Tinggi } \\
\text { Tanaman }(\mathrm{cm})\end{array}$ & $\begin{array}{c}\text { Rerata Banyak } \\
\text { Daun (helai) }\end{array}$ \\
\hline P1 (POH 30 ml/ liter dan NPK 0 g/ tanaman) & 89.2 & 12.4 \\
P2 (POH 22,5 ml/ liter dan NPK 1,8 g/ tanaman) & 97.932 & 12.6 \\
P3 (POH 15 ml/ liter dan NPK 3,6 g/ tanaman) & 56.1 & 8.2 \\
P4 (POH 7,5 ml/ liter dan NPK 5,4 g/ tanaman) & 68.592 & 8.8 \\
P5 (POH 0 ml/ liter dan NPK 7,2 g/ tanaman) & 89.532 & 12.2 \\
P6 (NPK 0 g/ tanaman) & 55.9 & 7.8 \\
P7 (NPK 1,8 g/ tanaman) & 99.792 & 12.2 \\
P8 (NPK 3,6 g/ tanaman) & 64.888 & 9.8 \\
P9 (NPK 5,4 g/ tanaman) & 91.044 & 12 \\
P10 (NPK 7,2 g/ tanaman) & 89.312 & 12.4 \\
\hline
\end{tabular}

Perlakuan P1 sampai dengan P5 dibahas untuk mengetahui kombinasi POH dan NPK mana yang optimal. Secara umum, perlakuan P2 memiliki pertumbuhan yang lebih baik jika dibanding perlakuan lain, karena memiliki tinggi tanaman yang tinggi dan banyak daun yang banyak. Dapat dikatakan bahwa perlakuan P2 dapat digunakan pada penanaman dengan tanah steril dan mendapat hasil yang paling lebih baik.

Perlakuan P6 sampai P10 dibahas didalam pembentukan sistem fuzzy. Pada pembahasan ini diformulasikan 2 sistem fuzzy. Sistem fuzzy 1 digunakan untuk menentukan output tingkat pertumbuhan dengan input tinggi tanaman dan banyak daun, sedangkan sistem fuzzy 2 digunakan untuk menentukan output konsentrasi $\mathrm{POH}$ dengan input tingkat pertumbuhan dari sistem fuzzy 1 dan konsentrasi NPK.

Variabel fuzzy yang diformulasikan pada sistem fuzzy 1 adalah variabel fuzzy tinggi tanaman dan variabel fuzzy banyak daun sebagai variabel input, dan variabel fuzzy tingkat 
pertumbuhan sebagai variabel output. Variabel fuzzy tinggi tanaman dibagi menjadi 3 himpunan fuzzy yaitu PENDEK, SEDANG, dan TINGGI.

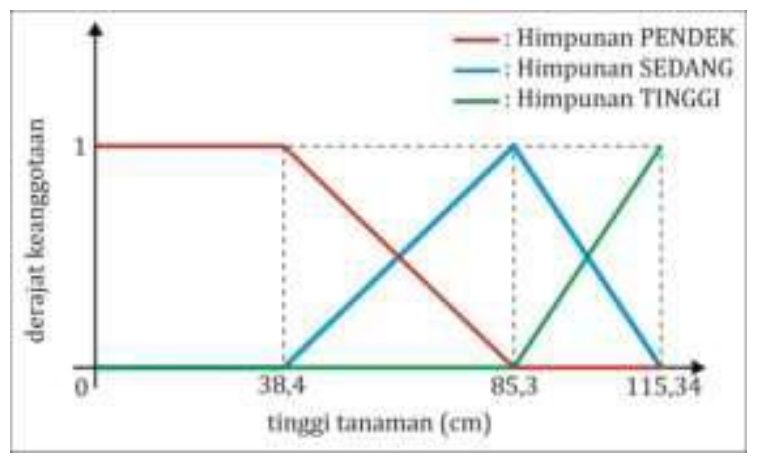

Gambar 1 Fungsi Keanggotaan Variabel Fuzzy Tinggi Tanaman

Variabel fuzzy banyak daun dibagi menjadi 3 himpunan fuzzy yaitu SEDIKIT, SEDANG, dan BANYAK.

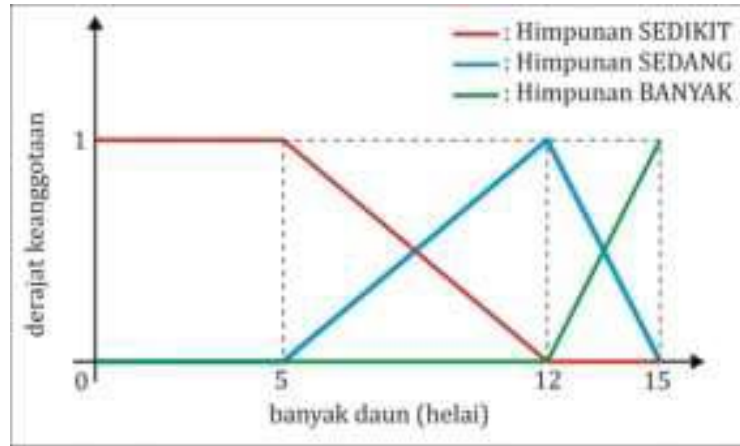

Gambar 2 Fungsi Keanggotaan Variabel Fuzzy Banyak Daun

Variabel fuzzy tingkat pertumbuhan dibagi menjadi 3 himpunan fuzzy yaitu RENDAH, SEDANG, dan TINGGI.

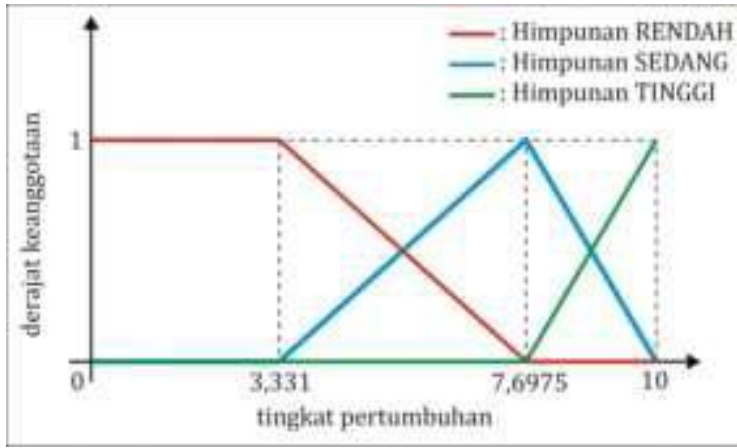

Gambar 3 Fungsi Keanggotaan Variabel Fuzzy Tingkat Pertumbuhan 
Kombinasi 3 himpunan pada variabel fuzzy tinggi tanaman dan 3 himpunan pada variabel fuzzy banyak daun didapat 9 aturan fuzzy.

Tabel 2 Aturan fuzzy sistem fuzzy 1

\begin{tabular}{cccc}
\hline Aturan & Tinggi Tanaman & Banyak Daun & Tingkat Pertumbuhan \\
\hline$[\mathrm{R} 1]$ & PENDEK & SEDIKIT & RENDAH \\
{$[\mathrm{R} 2]$} & PENDEK & SEDANG & RENDAH \\
{$[\mathrm{R} 3]$} & PENDEK & BANYAK & SEDANG \\
{$[\mathrm{R} 4]$} & SEDANG & SEDIKIT & RENDAH \\
{$[\mathrm{R} 5]$} & SEDANG & SEDANG & SEDANG \\
{$[\mathrm{R} 6]$} & SEDANG & BANYAK & SEDANG \\
{$[\mathrm{R} 7]$} & TINGGI & SEDIKIT & SEDANG \\
{$[\mathrm{R} 8]$} & TINGGI & SEDANG & SEDANG \\
{$[\mathrm{R} 9]$} & TINGGI & BANYAK & TINGGI \\
\hline
\end{tabular}

Pada tahap ini nilai input dari tinggi tanaman dan banyak daun direpresentasikan kedalam tiap aturan fuzzy, kemudian dilakukan implikasi dengan metode Min sehingga didapat derajat keanggotaan dari nilai output pada tiap aturan fuzzy.

Nilai hasil implikasi digunakan untuk memodifikasi himpunan fuzzy output kedalam luasan daerah, kemudian luasan daerah dari tiap aturan fuzzy dilakukan tahap inferensi dengan metode Max sehingga terbentuk luasan gabungan dari semua aturan fuzzy, yang disebut sebagai luasan daerah akhir.

Metode Centroid digunakan dalam defuzzifikasi, nilai tegas dari output diperoleh dengan cara mengambil titik pusat $\left(z^{*}\right)$ pada luasan daerah akhir. Nilai yang didapat adalah nilai solusi yang dicari, yaitu nilai tingkat pertumbuhan.

Variabel fuzzy yang diformulasikan pada sistem fuzzy 2 adalah variabel fuzzy tingkat pertumbuhan dan variabel fuzzy konsentrasi NPK sebagai variabel input, dan variabel fuzzy konsentrasi POH sebagai variabel output. Variabel fuzzy tingkat pertumbuhan pada sistem fuzzy 2 sama dengan formulasi variabel fuzzy tingkat pertumbuhan pada sistem fuzzy 1. Variabel fuzzy konsentrasi NPK dibagi menjadi 2 himpunan fuzzy yaitu RENDAH dan TINGGI. 


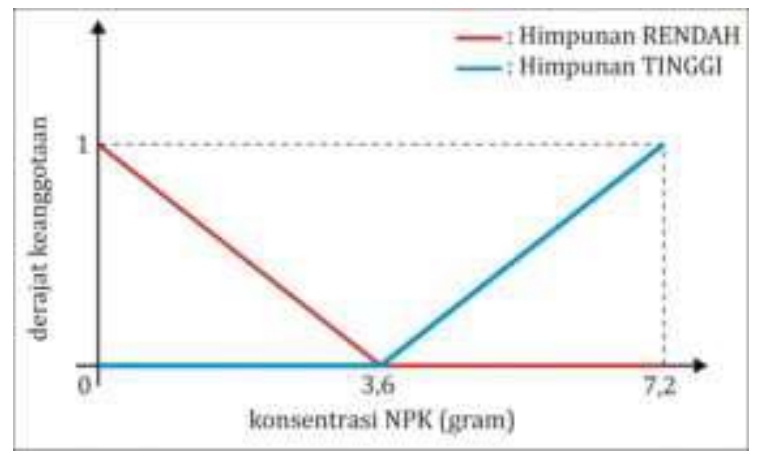

Gambar 4 Fungsi Keanggotaan Variabel Fuzzy Konsentrasi NPK

Variabel fuzzy konsentrasi POH dibagi menjadi 2 himpunan fuzzy yaitu RENDAH dan TINGGI.

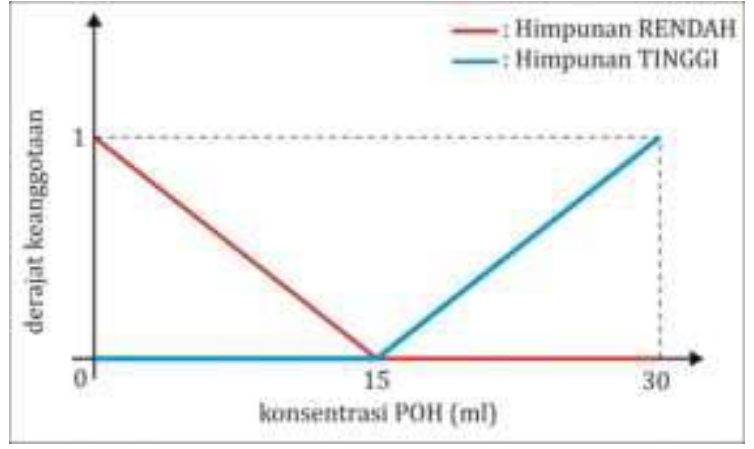

Gambar 5 Fungsi Keanggotaan Variabel Fuzzy Konsentrasi POH

Kombinasi 3 himpunan pada variabel fuzzy tingkat pertumbuhan dan 2 himpunan pada variabel fuzzy konsentrasi NPK didapat 6 aturan fuzzy.

Tabel 3 Aturan fuzzy sistem fuzzy 2

\begin{tabular}{|c|c|c|c|}
\hline Aturan & Tingkat Pertumbuhan & Konsentrasi NPK & Konsentrasi POH \\
\hline$[\mathrm{R} 1]$ & RENDAH & RENDAH & TINGGI \\
\hline$[\mathrm{R} 2]$ & RENDAH & TINGGI & RENDAH \\
\hline$[\mathrm{R} 3]$ & SEDANG & RENDAH & TINGGI \\
\hline$[\mathrm{R} 4]$ & SEDANG & TINGGI & RENDAH \\
\hline$[\mathrm{R} 5]$ & TINGGI & RENDAH & TINGGI \\
\hline$[\mathrm{R} 6]$ & TINGGI & TINGGI & RENDAH \\
\hline
\end{tabular}

Pada tahap ini nilai input dari tingkat pertumbuhan dan konsentrasi NPK direpresentasikan kedalam tiap aturan fuzzy, kemudian dilakukan implikasi dengan metode Min sehingga didapat derajat keanggotaan dari nilai output pada tiap aturan fuzzy.

Nilai hasil implikasi digunakan untuk memodifikasi himpunan fuzzy output kedalam luasan daerah, kemudian luasan daerah dari tiap aturan fuzzy dilakukan tahap inferensi 
dengan metode Max sehingga terbentuk luasan gabungan dari semua aturan fuzzy, yang disebut sebagai luasan daerah akhir.

Metode Centroid digunakan dalam defuzzifikasi, nilai tegas dari output diperoleh dengan cara mengambil titik pusat $\left(z^{*}\right)$ pada luasan daerah akhir. Nilai yang didapat adalah nilai solusi yang dicari, yaitu nilai konsentrasi $\mathrm{POH}$.

Hasil eksperimen dari P6 sampai dengan P10 kemudian diolah dengan menggunakan formulasi sistem fuzzy, dan hasil solusinya dapat dilihat pada Tabel 4.

Tabel 4 Hasil Solusi Sistem Fuzzy

\begin{tabular}{ccccc}
\hline Perlakuan & $\begin{array}{c}\text { Rerata } \\
\text { Tinggi } \\
\text { Tanaman }\end{array}$ & $\begin{array}{c}\text { Rerata } \\
\text { Banyak } \\
\text { Daun }\end{array}$ & $\begin{array}{c}\text { Tingkat } \\
\text { Pertumbuhan }\end{array}$ & $\begin{array}{c}\text { Konsentrasi } \\
\text { POH }\end{array}$ \\
\hline P6 (NPK 0 g/ tanaman) & 55.9 & 7.8 & 4.2668 & 24.8023 \\
P7 (NPK 1,8 g/ tanaman) & 99.792 & 12.2 & 6.9075 & 24.1667 \\
P8 (NPK 3,6 g/ tanaman) & 64.888 & 9.8 & 5.1274 & 15 \\
P9 (NPK 5,4 g/ tanaman) & 91.044 & 12 & 6.9883 & 5.833 \\
P10 (NPK 7,2 g/ tanaman) & 89.312 & 12.4 & 7.0167 & 5.1051 \\
\hline
\end{tabular}

Kemudian untuk melihat perbedaan pertumbuhan antara tanaman mentimun pada perlakuan P6 sampai dengan P10 awal dengan yang telah diberi POH akan dibandingkan dari hasil banyak mentimun pada hari panen, yang dapat dilihat pada Tabel 5.

Tabel 5 Perbedaan Hasil Panen Mentimun

\begin{tabular}{ccc}
\hline & \multicolumn{2}{c}{ Banyak Mentimun (buah) } \\
\cline { 2 - 3 } Perlakuan & $\begin{array}{c}\text { Tanpa } \\
\text { Penambahan POH }\end{array}$ & $\begin{array}{c}\text { Setelah } \\
\text { Penambahan POH }\end{array}$ \\
\hline P6 (NPK 0 g/ tanaman) & 1.2 & 1.8 \\
P7 (NPK 1,8 g/ tanaman) & 1.8 & 2.2 \\
P8 (NPK 3,6 g/ tanaman) & 1 & 1.4 \\
P9 (NPK 5,4 g/ tanaman) & 1.6 & 1.8 \\
P10 (NPK 7,2 g/ tanaman) & 2.2 & 3.2 \\
\hline
\end{tabular}

Pada Tabel 5 dapat disimpulkan bahwa tanaman mentimun pada perlakuan P6 sampai dengan P10 yang telah diberi POH menghasilkan pertumbuhan yang lebih baik sehingga mendapatkan hasil panen yang lebih banyak. 


\section{KESIMPULAN}

Berdasarkan hasil dan pembahasan mengenai penelitian yang telah dilakukan dapat disimpulkan bahwa metode fuzzy Mamdani dengan defuzzifikasi Centroid dapat digunakan untuk menentukan kombinasi optimal pupuk organik hayati dan NPK pada tanaman mentimun, dan mendapatkan hasil yang lebih baik. Tanaman mentimun yang telah diberikan $\mathrm{POH}$ dengan konsentrasi yang dihitung menggunakan sistem fuzzy yang telah diformulasikan menghasilkan hasil panen yang lebih baik daripada tanaman mentimun yang belum diberikan $\mathrm{POH}$.

\section{REFERENSI}

[1] Kusumadewi, S., dan Hari Purnomo. 2010. Aplikasi Logika Fuzzy untuk Pendukung Keputusan Edisi 2. Yogyakarta: Graha ilmu.

[2] Sarkar. A., Sahoo G., and Sahoo U. C. 2012. Aplication of Fuzzy Logic in Transport Planning. International Journal on Soft Computing (IJSC). Vol. 3, No. 2, Pp. 1-21.

[3] Mehan, Sandeep. 2011. Introduction of Traffic Light Controller with Fuzzy Control System. IJECT. Vol. 2, Issue 3, Pp. 119-122.

[4] Homaei, H., Hejazi S. R., and Dehghan Seyed A. M. 2015. A New Traffic Light Controller Using Fuzzy Logic for a Full Single Junction Involving Emergency Vehicle Preemption. Journal of Uncertain Systems. Vol. 9, No. 1, Pp. 49-61.

[5] Dahiru, Ahmed Tijjani. 2015. Fuzzy Logic Inference Applications in Road Traffic and Parking Space Management. Journal of Software Engineering and Applications. Vol. 2015, No. 8, Pp. 339-345.

[6] Demetgul, Mustafa, Ulkir Osman, Waqar Tayyab. 2014. Washing machine using fuzzy logic. Automation, Control and Intelligent Systems. Vol. 2, No. 3, Pp. 27-32.

[7] Sylvia, David M., Fuhrmann, Jeffry J., Hartel, Peter G., and Zuberer David A. 2005. Principles and Applications of Soil Microbiology Second Edition. New Jersey: Prentice Hall.

[8] Khasanah, Mukharom N. 2012. Pengaruh Pupuk NPK Tablet dan Pupuk Nutrisi Organik Cair Terhadap Pertumbuhan Bibit Kelapa Sawit (Elaeis guineensis Jacq.) di Pembibitan Utama. Fakultas Pertanian, Universitas Riau.

[9] Wahyujanti, Si Teguh. 2009. Implementasi Metode Fuzzy Logic Untuk Pengaturan Kelembaban Tanah Pada Tanaman Cabai. EEPIS, ITS.

[10] Ramdani, dan Teguh Budi Santoso. 2016. Penerapan Fuzzy Inference Sistem Untuk Kontrol Suhu Dan Kelembaban Budidaya Jamur Tiram Berbasis Mikrokontroler. Jurnal Ilmiah Fakultas Teknik LIMIT'S. Vol. 12, No. 1, Hal. 15-26. 
[11] Rezaei Mohammad, Asadizadeh Mostafa, Majdi Abbas, Hossaini Mohammad Farouq, Prediction of representative deformation modulus of longwall panel roof rock strata using Mamdani fuzzy system, International Journal of Mining Science and Technology, Vol. 25, No. 1, 2015, Hal. 23-30.

[12] Mohammad Rezaei, Indirect measurement of the elastic modulus of intact rocks using the Mamdani fuzzy inference system, Measurement, Vol. 129, 2018.

[13] J. Sun, Y.P. Li, P.P. Gao, B.C. Xia, A Mamdani fuzzy inference approach for assessing ecological security in the Pearl River Delta urban agglomeration, China, Ecological Indicators, Vol. 94, No. 1, 2018. 